\title{
EFFECT OF GRAIN ORIENTATION ON ALUMINUM RELOCATION AT INCIPIENT MELT CONDITIONS
}

\author{
Nadir Yilmaz ${ }^{1, *}$, Francisco M. Vigil ${ }^{1}$, Miquela S. Vigil ${ }^{1}$, Robert Branam ${ }^{1}$, Greg \\ Tolendino $^{2}$, Walt Gill ${ }^{3}$, A. Burl Donaldson ${ }^{3}$ \\ 1,* Department of Mechanical Engineering, New Mexico Institute of Mining and \\ Technology, Socorro, NM 87801, U.S.A \\ ${ }^{2}$ Department of Mechanical Engineering, New Mexico State University, Las Cruces, NM \\ 88003, U.S.A \\ ${ }^{3}$ Fire Sciences and Technologies, Sandia National Laboratories, Albuquerque, NM \\ 87123, U.S.A \\ *Correspondence to: Nadir Yilmaz, Department of Mechanical Engineering, New \\ Mexico Institute of Mining and Technology, Socorro, NM 87801, U.S.A. \\ †E-mail: yilmaznadir@yahoo.com , Phone: (575)835-5304, Fax: (575)835-5209
}

\begin{abstract}
Aluminum is commonly used for structural applications in the aerospace industry because of its high strength in relation to its weight. It is necessary to understand the mechanical response of aluminum structures at elevated temperatures such as those experienced in a fire. Aluminum alloys exhibit many complicated behaviors that require further research and understanding, such as aluminum combustion, oxide skin formation and creep behavior. This paper discusses the effect of grain orientation on aluminum deformation subjected to heating at incipient melt conditions. Experiments were conducted by applying a vertical compressive force to aluminum alloy 7075 block test specimens. Compression testing was done on test specimens with the applied load on the long transverse and short transverse orientations. Results showed that the grain orientation significantly influences aluminum's strength and mode of failure.
\end{abstract}

Keywords: Aluminum Deformation, Compressive Strength, Oxide Skin, Creep. 


\section{INTRODUCTION}

Aluminum is extensively used in the aerospace industry as well as other engineering fields and yet its behavior is not well understood at temperatures greater than $0.8 T_{m}$ in scenarios such as a fuel fire. This work is part of a broader study investigating the mechanical integrity of legacy alloy 7079 hardware subjected to abnormal environments. However, due to the deprecation of alloy 7079 and its limited availability experiments are conducted using a metallurgically similar material, alloy 7075 . When aluminum is heated in an air/oxygen or nitrogen rich environment, a thin oxide or nitride layer forms on its surface, respectively. This oxide layer behaves as a skin that covers the un-oxidized alloy and provides extra strength to the material while being deformed. Aluminum deformation is primarily dominated by creep at temperatures above $0.5 T_{m}$ in abnormally high heating conditions. In the occurrence of an accident resulting in a fire, it is important to understand what happens to aluminum alloys and how they deform during exposure to intense heat. In order to understand aluminum behavior in an accident scenario involving a long burning fire, important research topics that merit further investigation include oxide layer formation, oxide layer strength, creep behavior, combustion, and material characterization.

Syvertsen [2] measured the oxide skin strength on molten aluminum as a function of pure aluminum and aluminum alloys. It was assumed that the work per area needed to stretch and rupture the oxide skin is a combination of the interfacial tension and tensile strength of the oxide. It was determined that the oxide skin strength increases with increasing temperature for temperatures above $750{ }^{\circ} \mathrm{C}$. 
Constitutive models have been created to investigate creep behavior of aluminum alloys. These models take into account the overall strength rather than studying the oxide skin and the molten aluminum separately. The parameters for the constitutive models are usually determined by tensile or compression testing. A Gleeble thermo-mechanical simulator is used for tensile tests to measure stress-strain characteristics either at constant load or strain rate. Then experimental data can be used to determine creep law parameters by fitting it to equations. Farup et al. [3] used the Gleeble to measure temperatures and strain rates for thermally induced deformations in direct chill (DC) castings and fitted the experimental data to Garofalo's equation. Yousefiani et al [4] investigated the creep rupture mechanisms of annealed and overheated alloy 7075 at $647 \mathrm{~K}$ under uniaxial, biaxial, and triaxial stress states and examined samples before and after testing using optical microscopy, scanning electron microscopy (SEM), and transmission electron microscopy (TEM). Annealed and overheated samples were tested in short transverse and long transverse directions to understand the effect of microstructure and orientation on multi-axial creep rupture behavior in alloy 7075 . The results indicated suppression of grain boundary sliding (GBS) which was supported by observation of large particles at grain boundaries for the overheated samples and few or no particles at boundaries in the annealed samples. Also, annealed alloy 7075 rupture behavior was dominated by cavitation coupled with GBS regardless of sample orientation. But, creep deformation and cavity growth were mainly affected by dislocation creep and not coupled with GBS for the overheated alloy 7075 .

Kandare et al. [5] presented a creep-based modeling approach based on the work by Maljaars et al. [6] and evaluated the structural response of an aluminum plate under a 
combination of compression loading and one-sided heating by fire. Results showed that the model can predict buckling failure of simple aluminum columns when exposed to fires that experience temperatures in excess of $200{ }^{\circ} \mathrm{C}$.

In this work, two aluminum alloy 7075 blocks of different grain orientation were compression loaded inside a furnace at $590{ }^{\circ} \mathrm{C}$. Buckling was observed in the blocks to determine the influence of grain orientation on aluminum deformation in temperatures similar to those experienced in a fire.

\section{EXPERIMENTAL SETUP AND INSTRUMENTATION}

Aluminum 7075 was chosen as it is commonly used in many areas of aerospace construction such as aircraft frames. The microstructure of the compression test specimens was examined before and after heating. A $7.62 \mathrm{~cm}$ x $7.62 \mathrm{~cm}$ x $2.54 \mathrm{~cm}$ block

of cold drawn alloy 7075 was used to manufacture the test specimens. Samples of the bulk material from which the compression specimens were cut were set in epoxy resin, polished, and etched. The etchant used was in accordance with ASTM E407 \#3 (commonly called Keller's). Samples were exposed to the etchant for about 15-30 seconds. Micrographs were taken of each grain orientation at 200x magnification to determine the grain flow direction.

The testing apparatus used for compression testing consisted of a bell jar that served as an enclosure to control the atmosphere. Within the bell jar, a furnace was assembled using two resistive ceramic heater plates and compressed alumina insulation to reduce heat losses. The mechanical load was applied with a rotary-linear, direct manipulation, feed-through plunger. A stainless steel guide rod was then attached to the plunger. The 
guide rod ensured that the $0.775 \mathrm{~kg}$ load was applied to the compression specimen uniformly.

Several initial tests were conducted in order to determine which set point temperature would induce buckling with the given mechanical load. If too high of a temperature was used, complete structural failure of the specimen occurred and no useful observations could be made. A set point temperature of $590{ }^{\circ} \mathrm{C}$ was chosen, although an accuracy of only $\pm 10{ }^{\circ} \mathrm{C}$ was achievable due to the lag in the heating capabilities of the furnace. Figure 1 shows how the test specimen and steel weight were oriented within the furnace for the experiment in which the force was parallel to the short transverse orientation. For the second test specimen, the mechanical load was applied parallel to the grain flow as can be seen in Figure 2.

\section{RESULTS AND DISCUSSION}

\subsection{Grain Orientation}

The bulk material used for testing was cold drawn. This process creates elongated grains with a distinct grain flow in the direction that the material was drawn. Micrographs of the short transverse and long transverse orientations of the grain structure are shown for unheated and heated alloy 7075 samples below in Figure 3. The material from a block was heated to $590{ }^{0} \mathrm{C}$ and had a load applied to it in the long transverse orientation. The grain flow direction can be observed to be horizontal across the micrograph in images (a) and (b). A comparison of the short transverse view shows significant grain growth in the heated sample. Grain growth appears to be greater perpendicular to the direction of grain flow. The darkened grains in the heated sample's 
short transverse view (b) are likely due to the etchant used. Inspection of the long transverse view before and after heating shows noticeable equilateral grain growth. The large black portions seen in the long transverse view of the sample after heating (d) are suspected to be voids that formed by metallic hydrogen changing phases and escaping from the lattices or pockets of high energy material that coalesced at the grain boundary and were attacked by the etchant used while preparing the samples.

\subsection{Buckling of Aluminum 7075 Block}

While performing the initial experiments to determine which set point temperature would yield the desired deformation, an aluminum test specimen was subjected to temperatures above liquidus. At a temperature of $700{ }^{\circ} \mathrm{C}$, the aluminum block lost all structural integrity and was crushed by the applied mechanical load. The added compressive strength of the test specimen likely came from its brittle oxide layer. Observations showed that the oxide skin deformed primarily in areas where un-oxidized molten aluminum alloy relocated to. This observation illustrates the importance of the oxide layer in maintaining structural integrity of the alloy at incipient melt conditions.

Video was taken of the test specimens while subjected to compression. The deformation of the test specimen that was loaded in the short transverse orientation can be seen in Figure 4. In this configuration, a shear force was applied to the grains. Figure 5 shows the deformation of the test specimen that was mechanically loaded in the long transverse orientation.

The images in Figure 4 show significant deformation at the base of the block loaded in the short transverse orientation. Its two faces swelled as the oxide layer contained the heated alloy and sheared from the base material at an angle of approximately $45^{\circ}$. 
However, the sides of the test specimen showed minimal deformation. Grains in the short transversely loaded specimen would have had to elongate in order for the sides of the block to have deformations in a similar manner to the block seen in Figure 5. The affect of grain orientation on deformation is readily seen when Figure 4 and Figure 5 are compared. The deformation observed in the test specimen loaded in the long transverse orientation occurred on both the faces and sides of the block. Deformation was localized to the bottom portion of the test specimen. Figure 6 shows a comparison of the two test specimens side by side, showing that the block loaded in the short transverse direction exhibited significant deformation vertically and on its faces while loading in the long transverse orientation experienced deformation equilaterally at the base. The block loaded in the long transverse orientation likely deformed less because of added strength provided by the linear grain structure.

\section{CONCLUSIONS}

Subjecting aluminum alloy 7075 blocks to compressive loading at incipient melt conditions showed that grain orientation affects the manner in which the alloy deforms. The test specimen loaded in the short transverse orientation showed extensive vertical deformation. Additionally, this specimen expanded significantly on its faces, but not on its sides. Mechanical loading of a specimen in the long transverse orientation only showed signs of deformation equilaterally around the base. Inspection of micrographs taken in each orientation showed that both specimens experienced significant grain growth after heating. Additionally, both specimens formed voids, although the long transverse orientation formed them to a greater extent. The results presented in this paper serve as preliminary testing that will guide future work that will utilize a laser 
extensometer to measure displacement on various points of the block under compression.

The displacement data will be integrated into a computational model to simulate aluminum alloys in accident scenarios.

\section{ACKNOWLEDGMENT}

Sandia is a multi-program laboratory operated by Sandia Corporation, a Lockheed Martin

Company, for the United States Department of Energy's National Nuclear Security

Administration under contract DE-AC04-94AL85000.

\section{REFERENCES}

[1] RTO-AG-AVT-140, NATO Science and Technology Organization, March 2011, chapter 24, 1-22.

[2] M. Syvertsen, Oxide skin strength on molten aluminum, Metall. Mater. Trans. B 37 (2004) 495-504.

[3] I. Farup, J-M Drezet, A. Mo, T. Iveland, J Therm Stresses 23 (2000) 47-58.

[4] A.Yousefiani, F.A. Mohamed, J.C. Earthman, Creep rupture mechanicsm in annealed and overheated 7075 Al under multiaxial stress states, Metall. Mater. Trans. A, 31 (2000) 2807-2821.

[5] E. Kandare, S. Feih, A. Kootsookos, Z. Mathys, B. Y. Lattimer, A. P. Mouritz, Creepbased life prediction modelling of aluminum in fire, Mat. Sci. Eng. A-Struct., 527(2010) 1185-1193.

[6] J. Maljaars, F. Soetens, and I. Katgerman, Constitutive model for aluminum alloys exposed to fire conditions, Metall. Mater. Trans. A, 39 (2008) 778-789. 


\section{FIGURES}

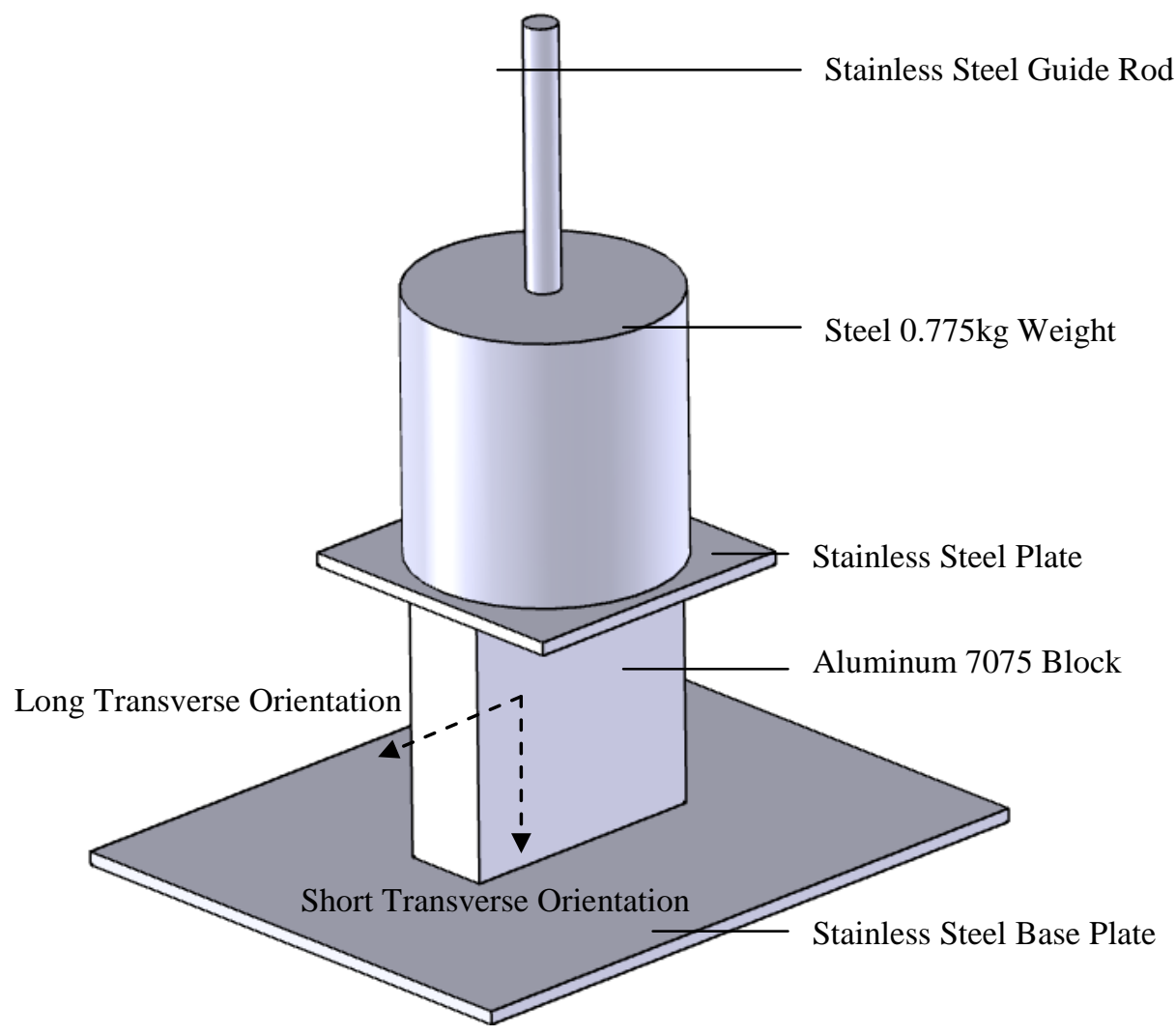

Figure 1. Initial aluminum 7075 block orientation 


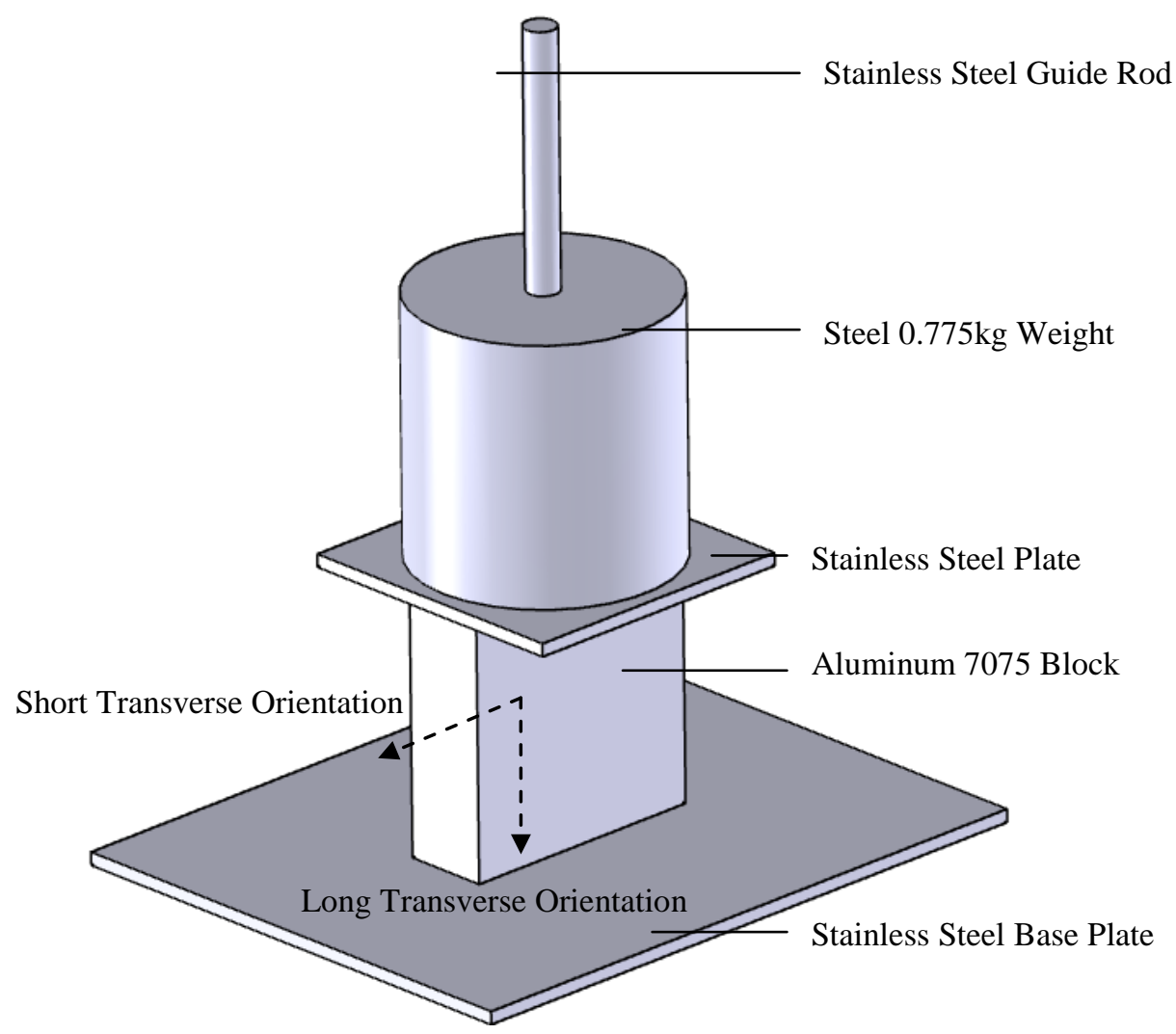

Figure 2. Orientation with mechanical load parallel to grain flow 

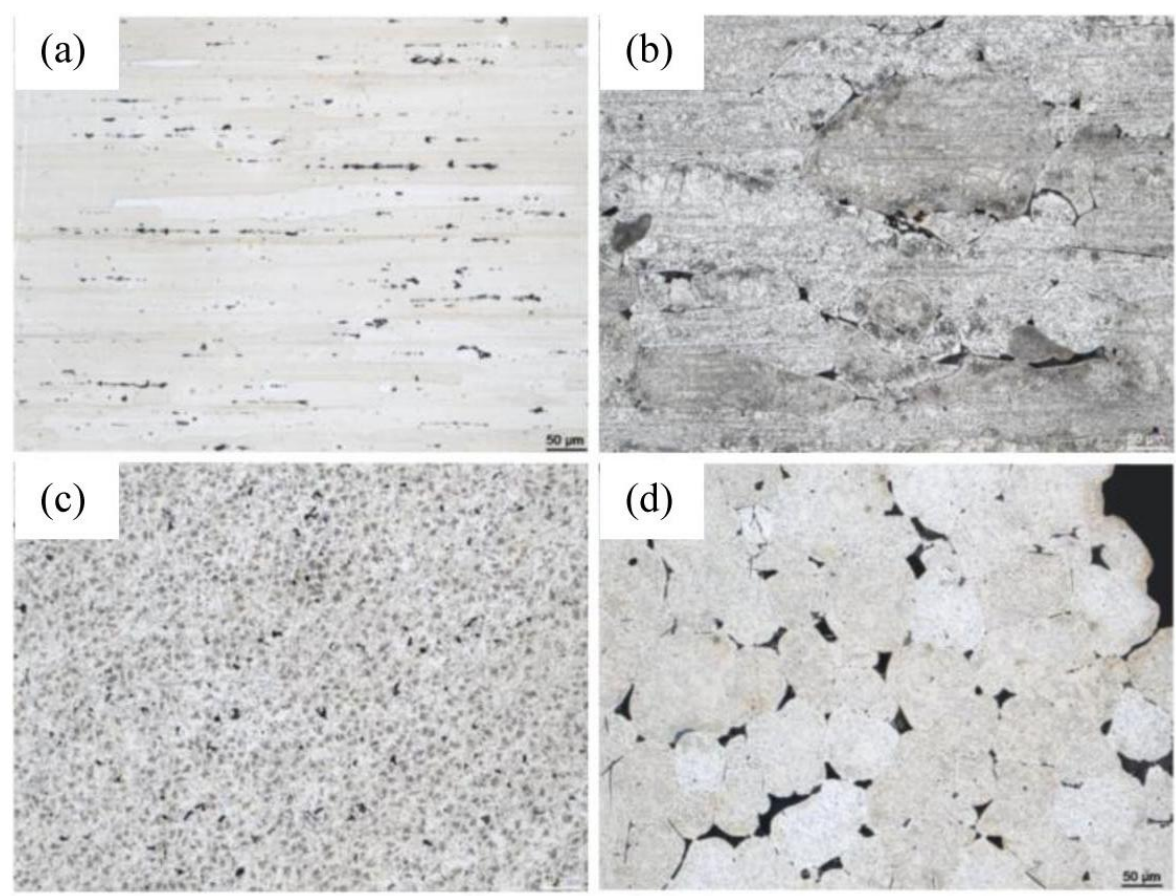

Figure 3. Micrographs of alloy 7075 before and after heating: (a) unheated short transverse, (b) heated short transverse, (c) unheated long transverse, and (d) heated long transverse 


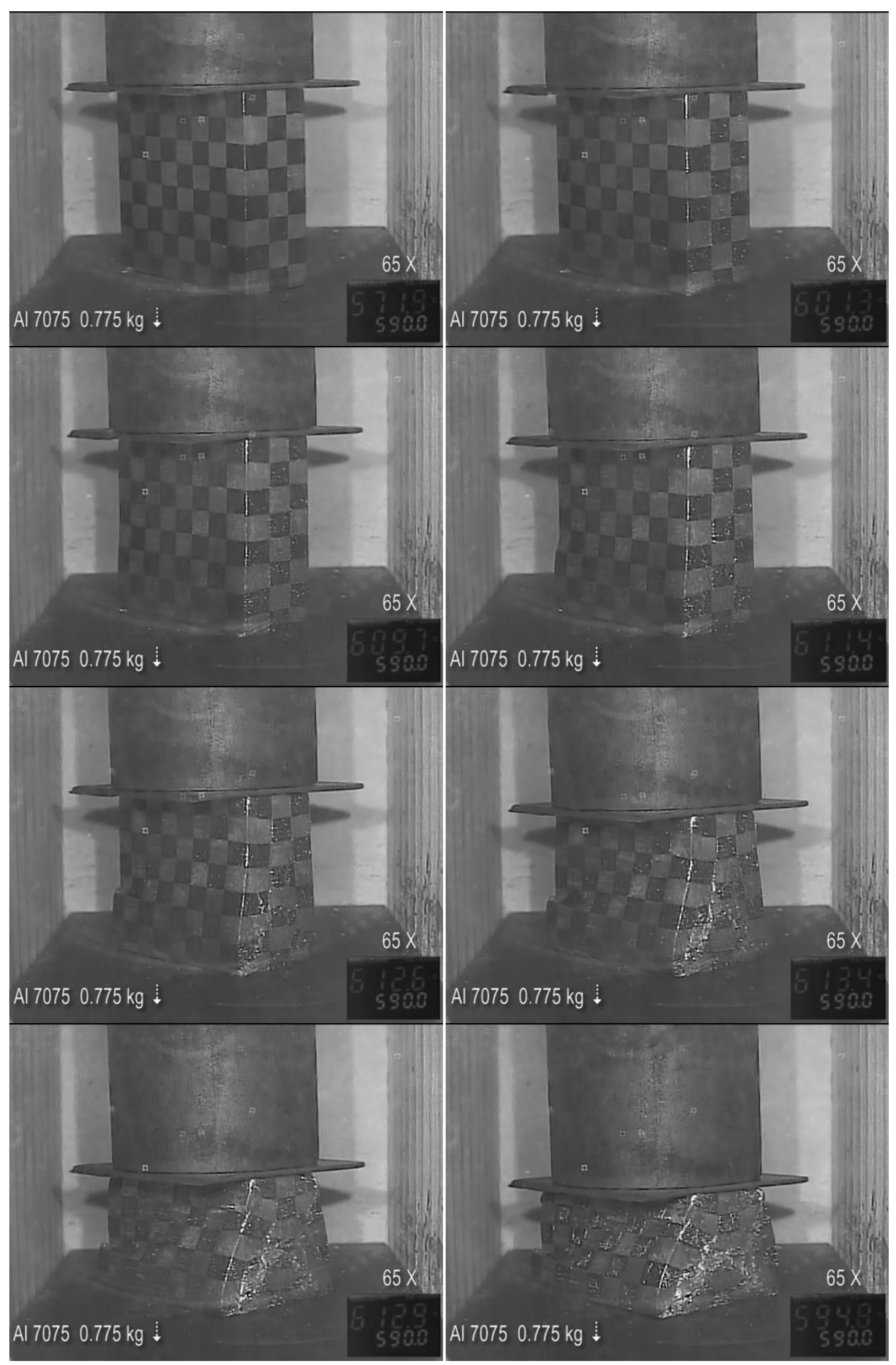

Figure 4. Aluminum 7075 block loaded in the short transverse orientation at $590{ }^{\circ} \mathrm{C}$ 


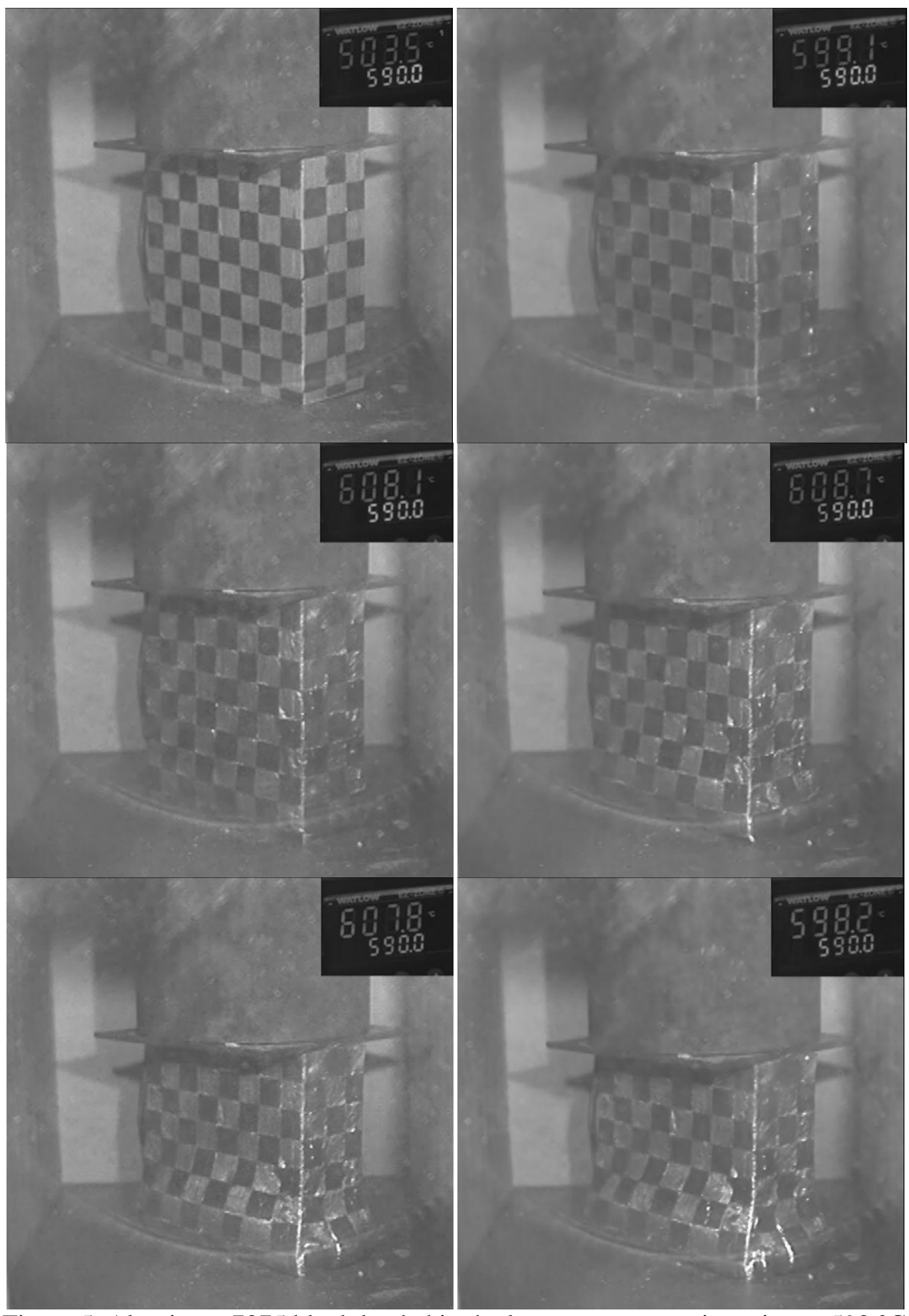

Figure 5. Aluminum 7075 block loaded in the long transverse orientation at $590{ }^{\circ} \mathrm{C}$ 


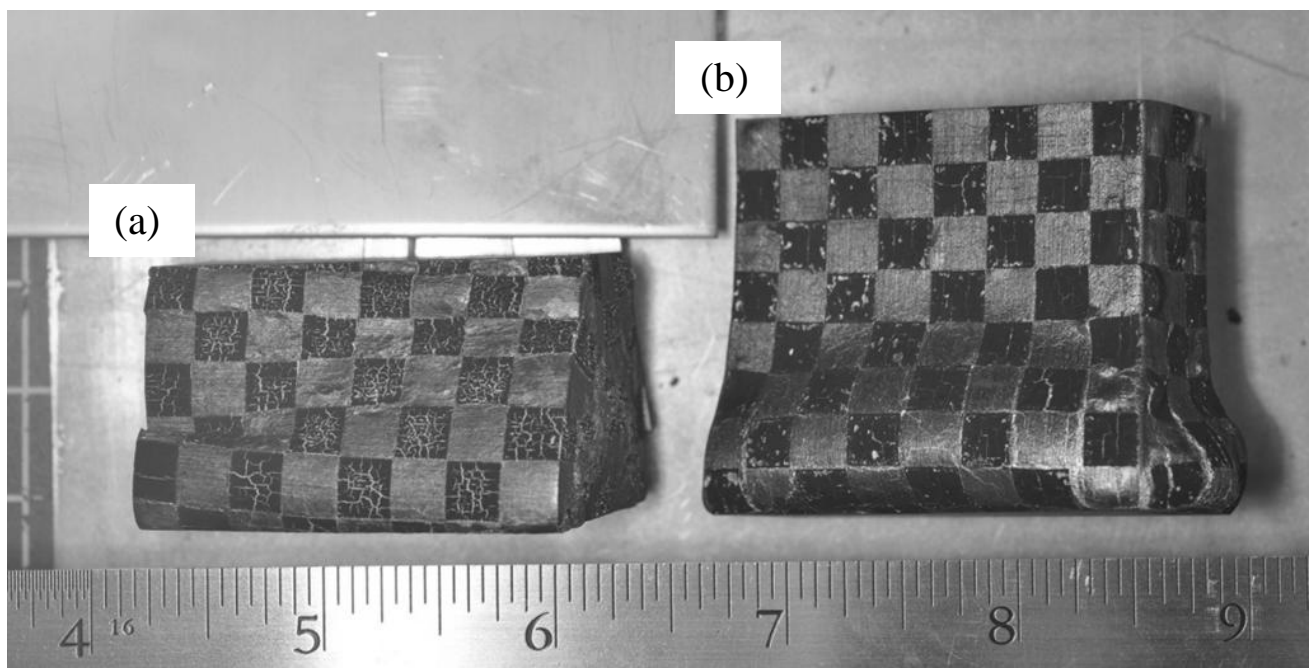

Figure 6. Comparison of deformed 7075 test specimens as loaded in the (a) short transverse and (b) long transverse orientations 